\title{
Algunas consideraciones acerca de los piercings orales
}

\author{
De Urbiola Alís I*, Viñals Iglesias $\mathrm{H}^{* *}$
}

\section{RESUMEN}

Desde la antigüedad se han venido realizando piercings intraorales con motivaciones muy diversas a lo largo de la historia. Actualmente es una moda que se ha generalizado en el mundo occidental. En este artículo se explican los distintos tipos de piercings intra y periorales, sus posibles localizaciones y las complicaciones derivadas de su uso. También se dan unas recomendaciones y unas pautas de tratamiento para los profesionales que deban atender a los pacientes portadores de piercings.

Palabras clave: Piercing oral-perioral, complicaciones orales, tratamiento odontológico.

\section{ABSTRACT}

Intraoral piercings have been worn for a long time. The reasons that have motivated their use changed along the years. Today intraoral piercings are worldwide spread. In this paper the different types of intraoral and perioral piercings are described together with their most frequent locations and possible complications. Some suggestions and guidelines on how to treat piercing-carriers-patients are given.

Key words: Oral-perioral piercing, oral complications, odontologic treatment.

Aceptado para publicación: Noviembre 2004.

* Estudiante de Odontoestomatología. Facultad de Odontología.Universidad de Barcelona.

** Profesor Asociado de Medicina Bucal. Facultad de Odontología. Universidad de Barcelona.

De Urbiola Alís I, Viñals Iglesias H. Algunas consideraciones acerca de los piercings orales. Av. Odontoestomatol 2005; 21-5: 259-269.

\section{INTRODUCCIÓN}

Desde épocas ancestrales se practica la perforación de diferentes partes del cuerpo para llevar pendientes. Un pendiente es un elemento decorativo colocado en la oreja -o menos a menudo- en otra parte del cuerpo. La realización y el uso de tatuajes, piercings (del adjetivo inglés que significa penetrante), escarificaciones y marcas con hierro candente han pasado a denominarse "body art" y es una moda que ha ido ganando terreno de forma espectacular entre jóve- nes en los últimos años. En la antigüedad, era una costumbre de ciertas poblaciones que podían estar alejadas de nuestra cultura, pero actualmente se está prodigando en el mundo occidental $(1,2,3,4$, 5, 6, 7).

El significado del "body art" normalmente responde a demandas estéticas (5) pero en ocasiones supera el simple deseo de mejorar la imagen, siendo otros los motivos como la búsqueda de la propia identidad, la provocación, el riesgo, la osadía, la rebelión, 
el placer sexual y los trastornos mentales que en ocasiones llevan a perforarse zonas muy sensibles del cuerpo $(1,7,8,9,10,11)$.

El body piercing no es un invento de nuestro siglo ya que esta práctica se emplea desde hace unos 60.000 años. Muchas etnias se reconocían por collares u otras ornamentaciones; de esta forma se diferenciaban diversos grupos dentro de una misma población: los cazadores, la mujer del jefe de la tribu, los brujos, los guerreros, etc. En ocasiones era un símbolo de virilidad, coraje y realeza, mientras que en otras tenía un sentido puramente estético $(1,12)$. En el antiguo Egipto un pendiente en el ombligo significaba formar parte de la realeza. En la época romana los centuriones llevaban piercings en el pezón como símbolo de virilidad y coraje. En los templos Mayas y Aztecas los sacerdotes se colocaban un piercing en la lengua como signo de comunicación con los dioses. Los esquimales y los Aleuts colocaban piercings en el labio inferior de las niñas recién nacidas como parte de un ritual de purificación y en los varones adolescentes como ritual de tránsito hacia la pubertad. Los materiales empleados podian ser piedras, huesos o el marfil $(1,5)$. En Norteamérica también formaba parte de la tradición de la cultura Sioux $(1,13)$.Sin embargo, estas prácticas fueron cayendo en desuso con las influencias del cristianismo Europeo y Americano $(1,5)$.

Todavía en la actualidad en algunas zonas del Tercer Mundo se utilizan piercings orales por razones religiosas, tribales, sexuales o maritales. Como ejemplos, la tribu Surma de Etiopía se coloca grandes platos en el labio inferior y en igual ubicación una tribu brasileña, los Suya, lucen discos de madera (14) . Algunos pueblos del sur de la India se perforan la lengua con una broca para mantener un voto de silencio (1).

En países del Primer Mundo y hacia los años 80 estas tendencias fueron aumentando de forma vertiginosa entre la juventud debido a diferentes factores: grupos de música de rock, la moda de la exageración, la anormalidad, lo monstruoso, los modelos sociales... Una encuesta realizada en el año 2001 en la Universidad de Pace en Pleasentville (Nueva York) desvelaba que un $51 \%$ de los estudiantes llevaban algún tipo de piercing (excluyendo los del lóbulo de la oreja) y un $17 \%$ del total había tenido complicaciones médicas (15). Un estudio de Sean y cols. (3) indica que tanto los tatuajes como los piercings pueden ser unos marcadores de conductas de riesgo en jóvenes de entre 12 y 22 años de los Estados Unidos; en el estudio se realizaron unos cuestionarios, observándose que los portadores de tatuajes y/o piercings estaban más relacionados con alteraciones en las conductas alimentarias, el uso de drogas duras (cocaína, éxtasis,...) o blandas (tabaco, alcohol, marihuana), la actividad sexual (precocidad, número de parejas, uso de contraceptivos), las tendencias suicidas y la violencia, respecto al resto de adolescentes encuestados; el estudio también indicaba una mayor prevalencia de tatuajes y especialmente de piercings entre las chicas (36.7\% piercings en chicas frente un $10.1 \%$ entre chicos). Hay que decir que el tema es controvertido y no todos los autores relacionan el body art con estas tendencias de comportamiento (16), sin olvidar tampoco que son estudios realizados en países distintos al nuestro.

Sabemos que algunos estamentos como la Asociación Dental Americana se han posicionado en contra de los piercings orales y en algunos países se han formulado leyes para regularlos (17). En el año 2001 el Gobierno de la Generalitat de Catalunya -en España-, aprobó ciertas medidas aplicables a los establecimientos de tatuaje o de piercing con el objetivo de proteger la salud de los usuarios y del personal dedicado a estas actividades. Esta legislación a parte de incidir en la formación, también obligaba a todos los establecimientos a seguir ciertas normas de control: equipamiento de primeros auxilios, autorización de los ayuntamientos, vacunación del personal frente a la hepatitis $\mathrm{B}$ y el tétanos y la utilización de material de un solo uso $(18,19)$.

\section{TIPOS DE PIERCINGS}

Principalmente se distinguen tres tipos de piercings (Fig.1):

- Labrette: es una barra limitada en un extremo por una esfera y en el otro por un cierre en forma de un disco plano y liso (20) (Fig. 2); este tipo de piercing se coloca sobretodo en el labio inferior (5). 


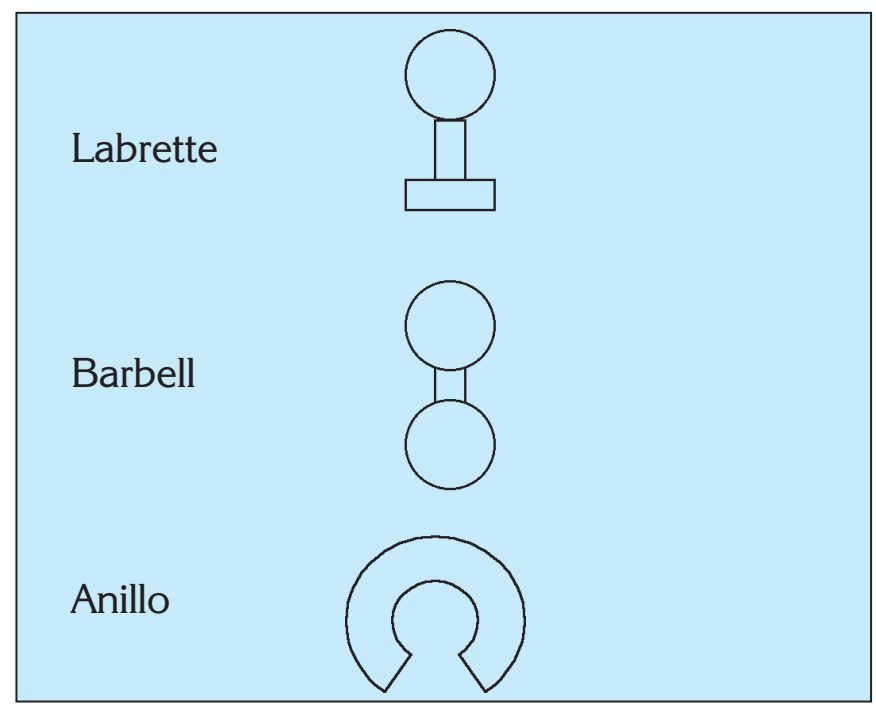

Fig. 1. Tipos de piercings.

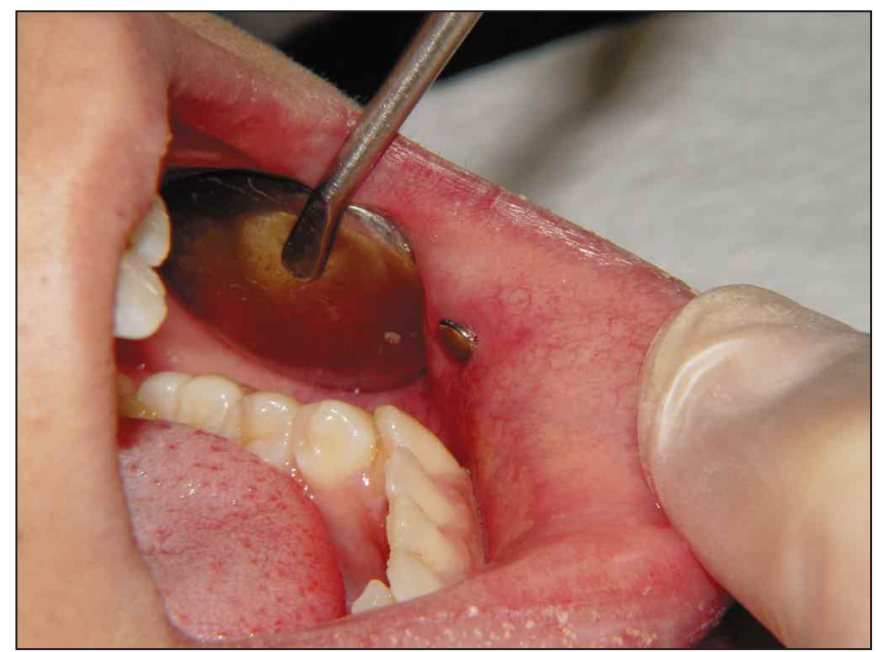

Fig. 2. Labrette.

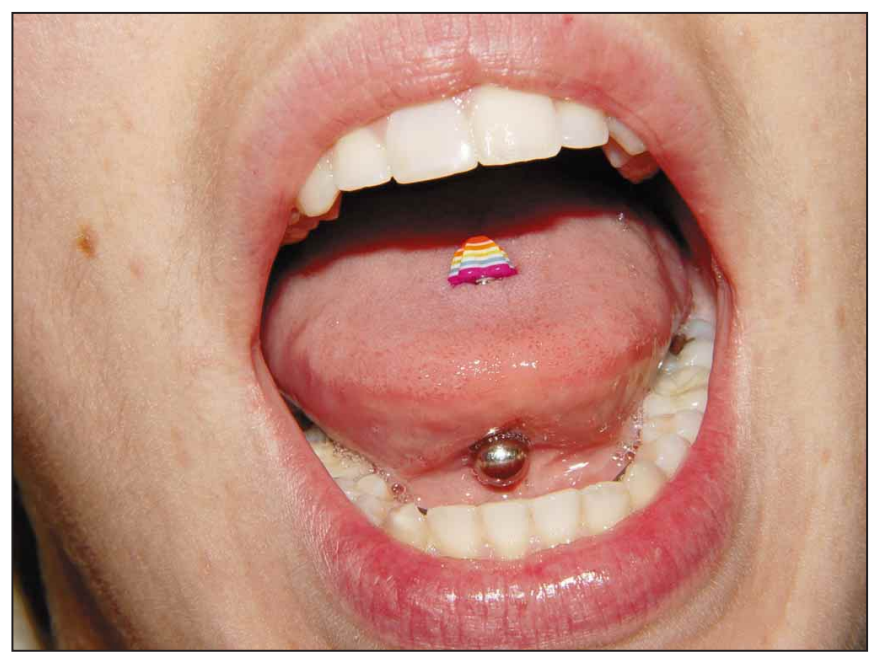

Fig. 3. Barbell.
- Barbell: es una barra limitada por dos esferas, una en cada extremo, siendo una de ellas el cierre $(1,12)$ (Fig. 3); las barras pueden ser rectas o curvas. Normalmente se colocan en la lengua (5). Inicialmente se mantienen con un tallo más largo y a las dos semanas -aproximadamente- se reemplazan por otros con el tallo más corto (4).

- Anillos: Normalmente se colocan en los labios y menos a menudo en zonas laterales de la lengua (5).

\section{LOCALIZACIONES ORALES}

La alta prevalencia de las perforaciones ha convertido en arte la originalidad, llegándose a perforar zonas muy poco convencionales. Los piercings intraorales y periorales pueden colocarse en $(1,20)$ :

- La lengua: es la zona más usual. Se pueden hacer dos tipos de perforaciones: dorsoventral o dorsolateral. En la zona dorsoventral, la perforación se realiza en esta dirección, normalmente es central y suelen colocarse barbells; en partes más laterales de la lengua y en la punta se colocan sobretodo anillos. La lengua puede ser objeto de varias perforaciones en diferentes zonas (Fig.4). En las perforaciones centrales, respecto a las laterales, hay menos riesgo de sangrado si se evitan los vasos sanguíneos mayores (1). La lengua, seguida del

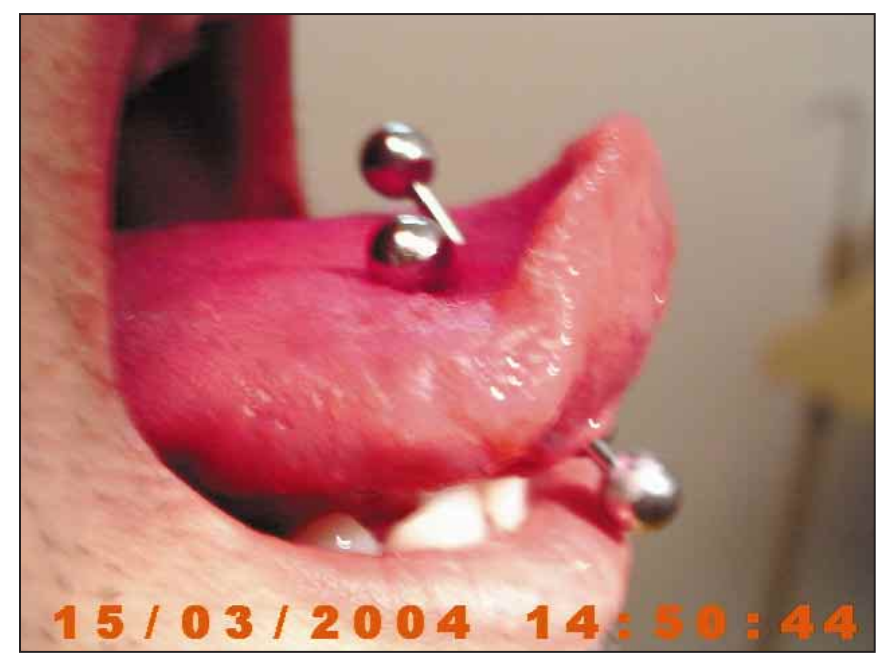

Fig. 4. Perforación múltiple lingual. 


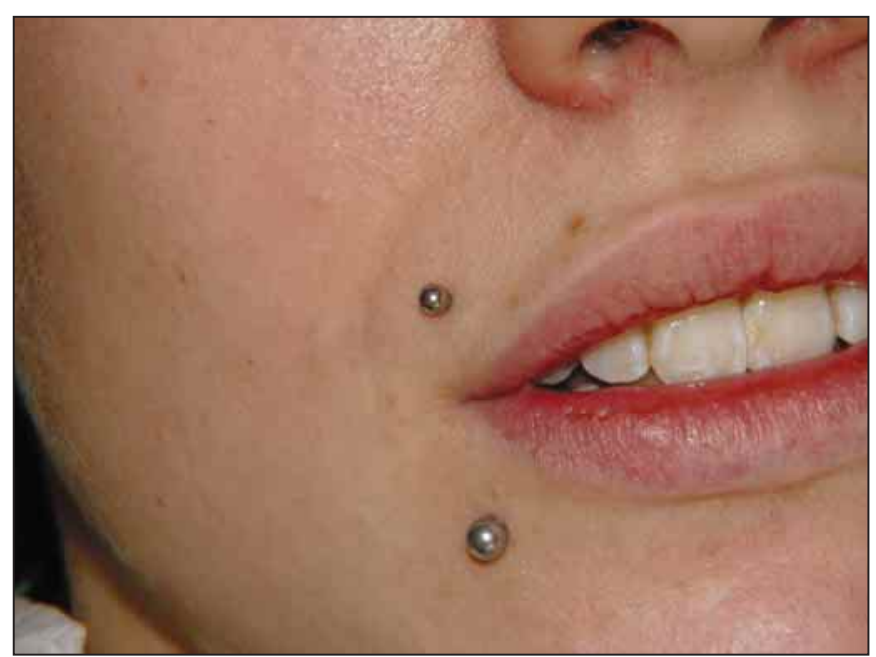

Fig. 5. Perforación múltiple labial.

labio inferior es la zona oral donde se colocan más piercings, con una prevalencia en Estados Unidos del 81 y $38,1 \%$ respectivamente $(6,7,21,22)$. El tiempo promedio de curación de la zona perforada es de unas 4 semanas $(5,32)$.

- El labio: puede perforarse en cualquier punto de su perímetro alrededor del borde bermellón $(1,5)$ (Fig.5). Es posible encontrar anillos cerca de la comisura labial o en el centro del labio inferior (6), pero en éste normalmente se colocan labrettes. Las perforaciones se realizan desde fuera hacia el interior de la cavidad oral (1).El tiempo promedio de curación de la herida tras la perforación es de unas 5 semanas (5).

- Las mejillas (conocidos como dimples): es una región poco utilizada (22). La perforación llega hasta la mucosa yugal y el piercing es externo.

- El frenillo lingual: son muy poco comunes (22). Se denominan "Web" piercing.

- La úvula: son muy raros por el elevado riesgo de complicaciones y por la dificultad de perforarla (22); muchos "pierciers" se niegan a colocarlos.

\section{CLÍNICA ASOCIADA A LAS COMPLICACIONES}

La clínica de las complicaciones puede presentarse durante la colocación del piercing, poco tiempo des-
TABLA 1.- COMPLICACIONES DE LOS PIERCINGS

Lesiones vasculares.

> Inflamación.

$>$ Dolor.

$>$ Lesiones nerviosas.

$>$ Infecciones:

- Locales.

- Bacteriemia.

- Transmisión de enfermedades.

- Endocarditis.

- Angina de Ludwig.

$>$ Alergias a los metales.

$>$ Traumatismos y fracturas dentarias.

$>$ Alteraciones periodontales.

- Acúmulo de placa bacteriana y cálculo.

$>$ Malposiciones dentarias.

$>$ Aspiraciones-ingestiones.

$>$ Sialorrea.

> Corrientes galvánicas.

> Alteraciones del habla/masticación/deglución.

> Lesiones hiperplásticas y epitelizacion de la superficie del piercing.

pués o a largo plazo (1). Comentaremos las principales complicaciones enunciadas en la Tabla 1:

\section{1.- Lesiones vasculares}

Las hemorragias son una complicación posible durante la perforación especialmente en un órgano tan vascularizado como es la lengua, que contiene la arteria y la vena lingual con sus diferentes vasos. Si la aguja traspasa alguna estructura vascular, la hemorragia se controla -en general- eficazmente, no obstante pueden producirse sangrados extremos que precisen atención sanitaria inmediata $(1,8,10,12)$.

\section{2.- Inflamación}

A las 6-8 horas tras una perforación lingual los tejidos circundantes empiezan a inflamarse, incrementándose el proceso durante los 3-4 días siguientes. Los ganglios submentonianos y submandibulares también pueden agrandarse por el proceso inflamatorio. Estos efectos pueden prolongarse algunas semanas (1). 


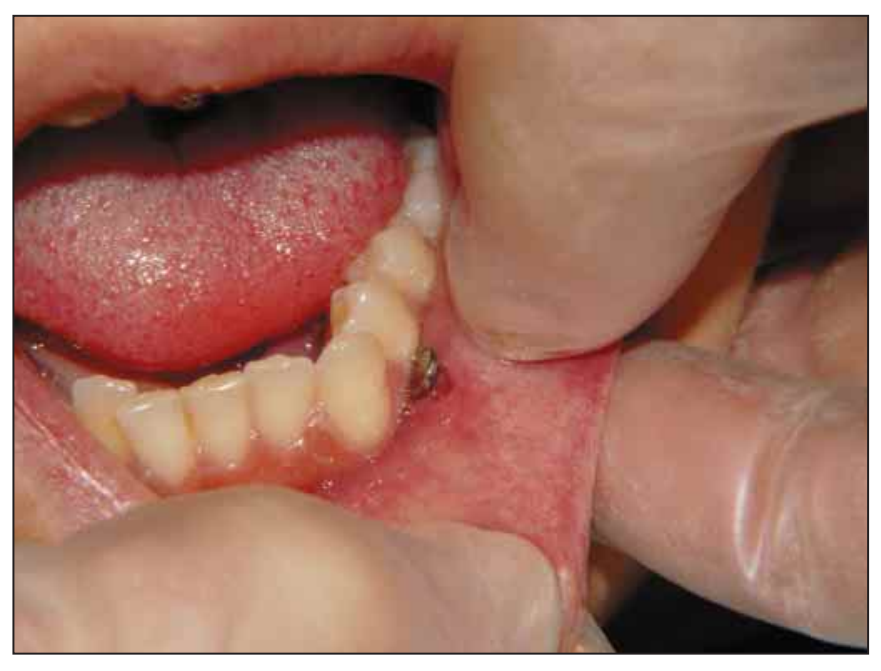

Fig. 6. Ulceración de la base del labrette.

Una lengua edematosa debida a la perforación con un objeto metálico, puede dificultar la alimentación, comprometer el habla o incluso la respiración, por la obstrucción de la vía aérea en el caso de formarse una angina de Ludwig, requiriendo una rápida atención del profesional $(1,8,12,13,23)$. Los labios igualmente pueden inflamarse tras la colocación de un piercing.

\section{3.- Dolor}

Los tejidos que rodean la herida causada por el piercing, debido a la inflamación o a la ulceración, provocan dolor (Fig.6). La inflamación y el dolor son -de hecho- las complicaciones más frecuentes (10). El tiempo necesario para que remitan totalmente los síntomas tras una perforación lingual se calcula entre 3 y 5 semanas (5).

\section{Lesiones nerviosas}

La lengua es un órgano inervado por diferentes pares craneales como el nervio trigémino, el facial, el hipogloso y el glosofaríngeo. Existe el riesgo de lesionar algún nervio durante la colocación de piercing, pudiéndose alterar el sentido del gusto o la función motora -en forma de parestesia- según el nervio afectado. Este tipo de lesiones son más frecuentes con los piercing dorsolaterales que con los dorsoventrales, pero pueden suceder con ambos $(1,8,12)$.

La pulpa dentaria también puede afectarse. El proce- so vendrá determinado por el continuo movimiento del piercing sobre el diente que puede provocar una fractura que ocasione finalmente una pulpitis $(1,12)$.

\section{5.- Infecciones}

5.1.- Infecciones locales: entre un 10 y un $20 \%$ de todos los piercings se infectan localmente. Los agentes causales más frecuentes son los estafilococos aureus, los estreptococos del grupo A y las pseudomonas (2).

5.2. Bacteriemia: Tras una colocación reciente, se deberá solicitar atención sanitaria si aparecen síntomas de bacteriemia como fiebre, escalofríos, temblores y un enrojecimiento circundante a la perforación (1).

5.3.- Transmisión de enfermedades: Se han descrito un reducido número de casos de hepatitis fulminante tras la colocación de piercings (2); sin embargo hay pocos estudios que constaten el riesgo de transmisión de enfermedades relacionadas con esta práctica. Potencialmente la infección podría deberse a una mala higiene, a instrumentos mal esterilizados o a un mal aislamiento del campo local, en centros donde normalmente también se realizan tatuajes. Podrían transmitirse virus como el HIV, la hepatitis B, $C$ y delta, el herpes simple, el Epstein-Barr, infecciones por cándidas o bacterias como el tétanos, las pseudomonas, los estafilococos aureus, los estreptococos, etc..(1,2,8,10,12,24).

5.4.- Endocarditis bacteriana: los piercings pueden provocar una grave infección del endocardio valvular en personas que sufren alteraciones cardíacas previas (6).

5.5.- Angina de Ludwig: es una infección bacteriana debida principalmente a un estreptococo hemolítico. Puede presentarse inmediatamente después de la perforación intraoral, provocando una celulitis difusa del suelo de la boca y de la región suprahioidea que afecta al tejido conectivo y se extiende rápidamente a la región submadibular, submental y sublingual. Esta infección puede dificultar el habla la deglución y la respiración llegando a comprometer la vida del paciente, por lo que es imprescindible un tratamiento urgente $(1,8,12)$. 


\section{6.- Alergias a los metales}

En función del tipo de material del piercing puede aumentar el riesgo de irritaciones crónicas o de hipersensibilidad al metal. Es importante una adecuada elección del tipo de material para evitar posibles complicaciones y una sustancia a evitar es el níquel. Un estudio realizado por Lhotka et al. (23) presentó una hipersensibilidad al níquel en el 18\% de hombres y en el $23 \%$ de mujeres junto con elevados índices de hipersensibilidades a otras sustancias como el cromo que hasta entonces formaban parte de la mayoría de los piercings. Diversos autores consideran como la reacción alérgica más común la dermatitis de contacto, dónde el níquel y cobalto juegan un papel importante $(23,25)$.

Según una directiva de la Unión Europea, a mediados de la década de los noventa, se restringió el uso de níquel en todos los productos que estuvieran en contacto directo con los tejidos humanos (23). Las sustancias metálicas más inertes y menos tóxicas inicialmente recomendadas para formar parte de los piercings eran el oro de $14 \mathrm{~K}$ o $18 \mathrm{~K}$, el niobium, el acero inoxidable y el titanio (2). El acero inoxidable ha demostrado una buena biocompatibilidad, pero una de sus principales limitaciones en el uso clínico es su tendencia a la corrosión por su contenido en cromo y niquel, elementos bien conocidos por sus efectos tóxicos y carcinogenéticos. Sin embargo el acero inoxidable conserva aún un importante lugar en la fabricación de piercings con un baño dorado. El oro es un material bien aceptado al tener una escasa o nula toxicidad, sin embargo algunos componentes pueden presentar cierta alergia o toxicidad en determinadas personas. Especialmente el titanio no presenta citotoxicidad y tiene una elevada resistencia a la corrosión en contacto con los fluidos orgánicos, siendo un material recomendable en la fabricación de los piercings (25).

\section{7.- Traumatismos y fracturas dentarias}

Son las lesiones más frecuentes descritas por el uso de los piercings intraorales $(5,22)$. El hábito de empujar y jugar con el pendiente contra los dientes o, simplemente, el hecho de tener un objeto extraño en la boca puede ocasionar fracturas, fisuras, abrasiones o desprendimientos de espículas de esmalte (chipping) provocando -sobretodo si existe implica-

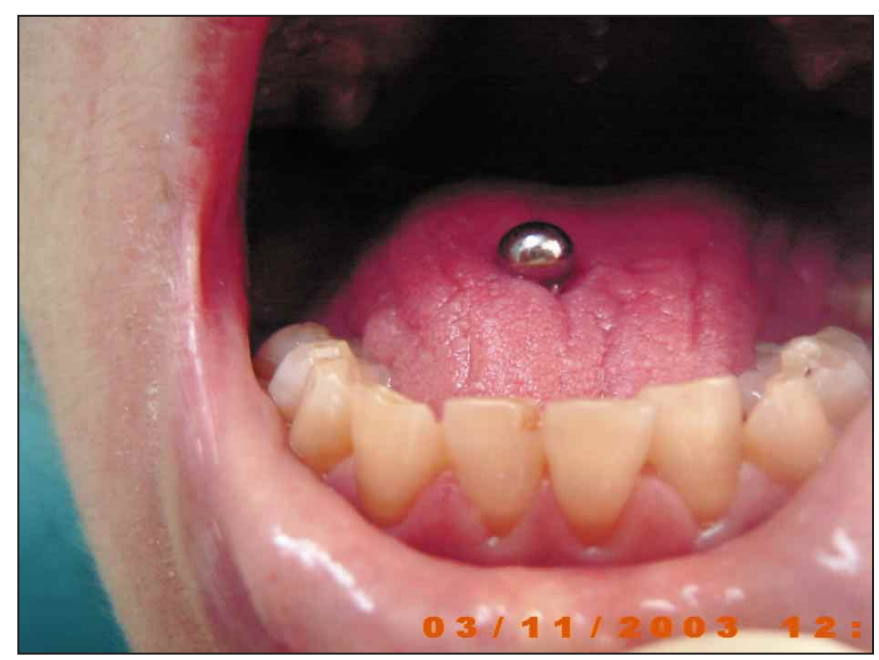

Fig. 7. Fracturas dentarias múltiples.

ción pulpar- sensibilidades a substancias frías o dulces y la aparición de dolor al ejercer una presión en el diente afectado $(1,8,13,22)$ (Fig. 7). De Moore et al. (12) registraron en un $80 \%$ de pacientes con un piercing lingual alguna pérdida en su estructura dentaria. Las complicaciones dentarias son más habituales en los portadores de barbells linguales (en la zona de molares e incisivos inferiores) que en los piercings labiales $(4,5)$

En los portadores de coronas de porcelana o con hábitos parafuncionales como el bruxismo, aumenta mucho el riesgo de fracturas o desgastes $(12,13)$.

\section{8.- Alteraciones periodontales}

La acción reiterada del traumatismo metálico contra el periodonto puede causar una leve, moderada o severa recesión gingival junto a traumas en los tejidos vecinos $(1,4,6,7,12,21,26,27)$ (Fig. 8). Las lesiones periodontales se relacionan en un $64.3 \%$ de casos con el uso de piercings linguales y en un $35.7 \%$ con los colocados en el labio inferior (22). En el estudio de Brooks et al.(22) se describen una serie de casos de recesión gingival por piercings; los colocados en la lengua provocaban la recesión en la cara lingual de los incisivos antero-inferiores junto con un aumento en la profundidad de las bolsas periodontales; los piercings colocados en el labio inferior provocaron recesiones en la cara vestibular de los incisivos inferiores sin aumentar la profundidad de las bolsas periodontales. El desarrollo de las recesiones en 


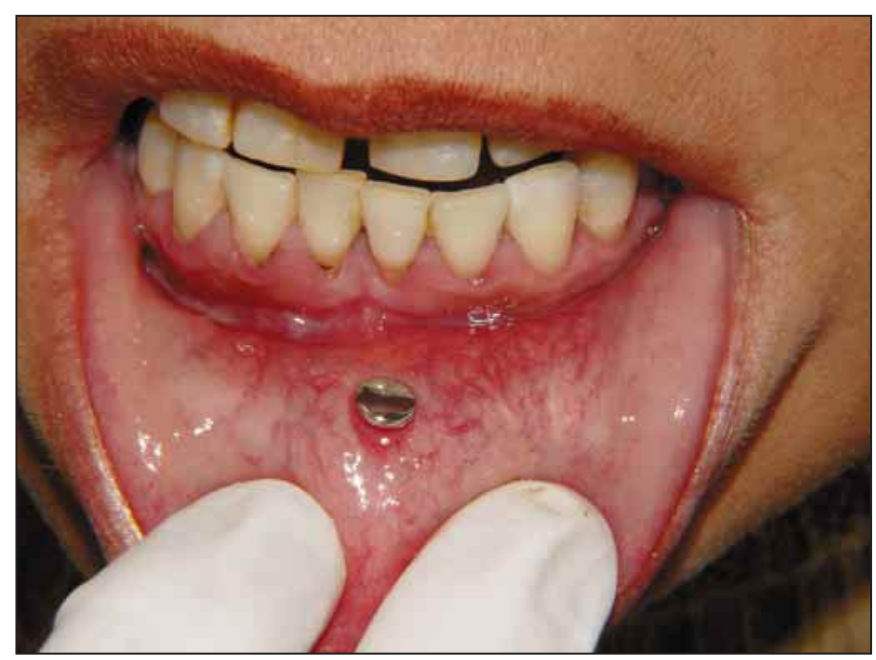

Fig. 8. Recesión periodontal.

la cara vestibular de los incisivos inferiores puede desarrollarse entre los 6 meses y los dos años tras la colocación del piercing (4). Campbell et al. (26) establecieron una correlación entre el número de recesiones, la longitud del tallo del barbell y la duración del uso del piercing. La recesión gingival -a parte de problemas de índole estético- puede provocar una abrasión de la superficie radicular con un aumento de la sensibilidad (4) y una predisposición a la caries en la zona expuesta (27). En ocasiones puede aparecer una hiperplasia de los tejidos afectados con edema y dolor como consecuencia de la lesión.

\section{9.- Acúmulo de placa bacteriana y formación de cálculo}

Kretchmer et al. (26) describen que la perforación lingual con un barbell puede provocar acúmulos de placa y cálculo supra y subgingival en dientes anteroinferiores debido a que la esfera inferior del piercing contacta continuamente con los dientes.

\section{Malposición dentaria}

En la Fig. 9 observamos una linguoversión de dos incisivos de la arcada inferior debido al trauma continuado del labrette sobre la superficie dentaria. La malposición se explica por un desequilibrio de las fuerzas musculares de la lengua frente al orbicular de los labios y el anillo del bucinador. En nuestra revisión de la literatura consultada no hemos encontrado descrita esta alteración.

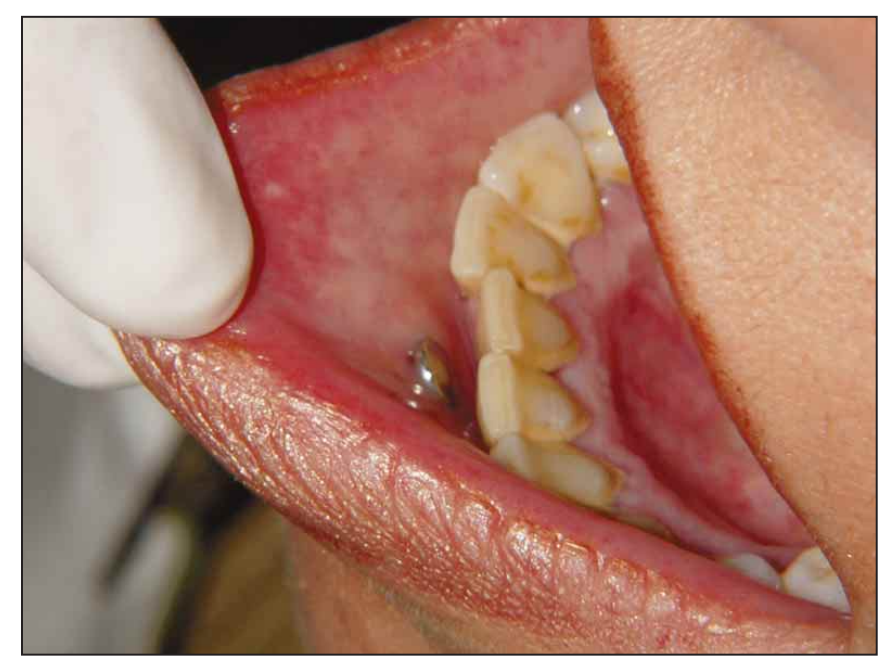

Fig. 9. Malposición dentaria por trauma continuado.

\section{1.- Aspiraciones e ingestiones}

La mala fijación del piercing puede provocar su aspiración o deglución, ocasionando lesiones en el aparato respiratorio o digestivo. Éstas también pueden deberse a la manipulación durante la colocación o a movimientos en los que se ejerce gran presión, por ejemplo en las comidas (1).

\section{2.- Sialorrea}

El contacto de un artefacto metálico en la boca puede estimular la producción de saliva, que incluso puede ser más fluida $(12,26)$. El efecto de estimulación salival fue descrito en 8 de 51 individuos en un estudio californiano (5).

\section{3.- Corrientes galvánicas}

Los pacientes pueden mostrar una hipersensibilidad en las restauraciones de amalgama en contacto con el metal del piercing $(1,10,12)$.

\section{4.- Alteraciones del habla, masticación o deglución} El piercing puede obstaculizar el habla al interferir los movimientos normales de la boca provocando defectos en la pronunciación. También la masticación y la deglución puede estar comprometidas debido a la interposición del objeto $(8,12,13,26)$.

\section{5.- Lesiones hiperplásicas y epitelizaciones del piercing}




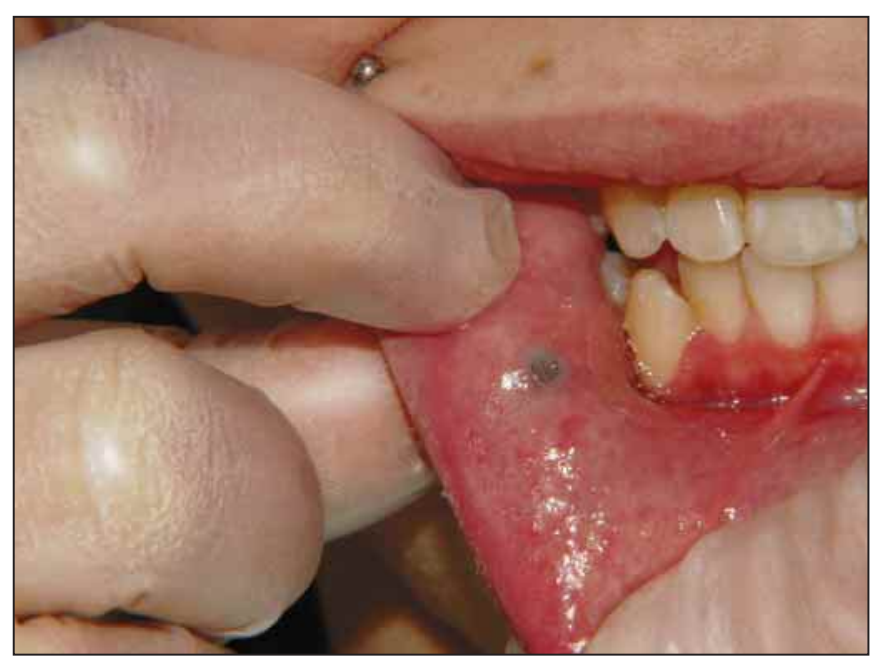

Fig. 10. Epitelización de la superficie del piercing.

La perforación de los tejidos blandos puede cicatrizar de forma hiperplásica $(1,8)$. Un factor que puede contribuir a las lesiones hiperplásicas es el movimiento continuado del piercing en el tejido sobre el que se inserta (5).

La herida causada por la colocación del piercing puede evolucionar -tras varios meses- con el recubrimiento epitelial del mismo (Fig.10), lo que supone una complicación en el momento en que se desea retirarlo $(2,4,10)$.

\section{DISCUSIÓN}

Los dentistas deben conocer los posibles riesgos de la colocación y el mantenimiento de los piercings intraorales para informar a sus pacientes $(1,2,4,6,10,11,13)$. No obstante, no podemos ignorar que la población portadora de tales ornamentos es en muchas ocasiones reacia a quitárselos (7), por lo que también deberemos recomendar y ofrecer tratamientos alternativos a los usuarios de los mismos.

Si el portador de un piercing consulta por una inflamación o un dolor grave, deberemos retirar el piercing y prescribir un colutorio o un gel de clorhexidina, un antinflamatorio sistémico, en algunos casos dar una terapia antibiótica, y realizar un seguimiento posterior (8). Los efectos de la inflamación inmediata tras la colocación de un piercing pueden ser paliados con enjuagues de suero salino o con los trata- mientos anteriormente descritos (1).Los piercings labiales respecto a los linguales parecen ser menos agresivos si consideramos el número de infecciones postoperatorias tras su colocación (5). En los casos en que la inflamación de la lengua sea generalizada, afecte a la faringe o comprometa a la deglución o a la vía aérea, el tratamiento será urgente con la administración de antibióticos y corticoides sistémicos (29).

Ante una Angina de Ludwig el tratamiento debe ser hospitalario, enérgico y multidisciplinario, con antibioticoterapia intensa acompañada de ciertas medidas -según la gravedad- como es el desbridamiento profiláctico de todos los espacios afectados y el control del grado de dificultad respiratoria.

Es importante pautar las medidas profilácticas frente a la endocarditis bacteriana (Tabla 2) en aquellas personas que quieran realizarse una perforación y presenten alguna alteración cardíaca susceptible $(6,30)$.

Para evitar las fracturas y los desgastes dentarios lo ideal es recomendar al paciente la retirada del piercing o como alternativa el uso de barbells linguales de tallo más corto (5); el tratamiento conservador deberá restaurar la superficie afectada y realizar una endodoncia si hay afectación pulpar; tras la restauración dentaria, la fractura puede recidivar en poco

\section{TABLA 2.- PAUTA PROFILÁCTICA FRENTE A LA ENDOCARDITIS BACTERIANA EN ADULTOS (American Heart Association, 1997) ${ }^{15}$}

> Pauta estándar: Amoxicilina 2 gr, por vía oral, 1 h. antes de la intervención.

> Alérgicos a la Penicilina: Clindamicina 600 mg., o Cefalexina/Cefadroxilo 2 gr o Azitromicina/Claritromicina 500 mg por vía oral 1 h. antes.

> Intolerancia a la vía oral: Ampicilina $2 \mathrm{gr}$, por vía i.m. o e.v., 30 min. antes.

> Alérgicos a la Penicilina con intolerancia a la vía oral: Clindamicina 600 mg por vía e.v. 30 min. antes; o Cefazolina $1 \mathrm{gr}$ im o ev. $30 \mathrm{~min}$. antes. 
tiempo si no se retira el piercing o si persiste el hábito de golpear y jugar con él ; es importante advertir a los pacientes de tal posibilidad (9); en estos casos están indicados los protectores dentales. Este consejo también debe darse a los atletas usuarios de piercings intraorales (4).

Tal y como describen diversos autores $(21,32)$, uno de los problemas del paciente que acude al odontólogo reside en que no siempre lleva puesto el piercing que usa normalmente y podemos encontrarnos con desgastes, roturas del esmalte de incisivos o de molares o recesiones gingivales de difícil explicación si no reconocemos el antecedente.

Ante la presencia de un acúmulo de placa bacteriana, cálculo supra o subgingival, recesiones gingivales y/ movilidad dentaria, deberemos aconsejar también la retirada del piercing; además daremos instrucciones de higiene oral, realizaremos una profilaxis y un raspaje y alisado radicular en la región afectada con el fin de reducir la inflamación, el sangrado gingival y la posible pérdida de soporte óseo (31). La progresión de la recesión gingival se detiene con la retirada del piercing, aunque el tratamiento definitivo puede implicar la cirugía del defecto tisular y el posterior control del paciente $(4,5,6,21,27)$. Es preciso realizar radiografías periapicales para valorar un posible ensanchamiento del espacio del ligamento periodontal y/o un adelgazamiento de la lámina dura (7).

Los pocos casos en que se presente un posible galvanismo, deben tratarse sustituyendo la obturación de amalgama por una resina como el composite; otra posibilidad es substituir el piercing metálico por otro material, ya sean sólo las esferas o los cierres o también la barra (12).

La presencia de un piercing en la cavidad oral puede interferir la práctica odontológica en diferentes momentos:

- Ante una exploración radiográfica puede ser necesario retirarlo ya que si es metálico representa un artefacto radiográfico que puede impedir la visualización de algunas estructuras. Si se trata de una radiografía panorámica debe retirarse cualquier objeto metálico situado por encima del cuello. Los piercings de la mejilla o del labio deben ser retira- dos antes de realizar radiografías periapicales o de aleta de mordida. Frente a un artefacto radiopaco en la radiografía deberemos plantearnos el diagnóstico diferencial con un piercing intraoral $(1,5,12)$.

- La necesidad o no de retirar el piercing para una anestesia local dependerá del criterio de cada profesional. En las anestesias tronculares -al afectar la lengua- se incrementa el riesgo de fractura dentaria hasta la total desaparición de la misma. Si se requiere anestesia general para una intervención quirúrgica existe la controversia sobre la necesidad o no de retirar el piercing (sobretodo los linguales);durante la anestesia el piercing podría ser aspirado, traumatizar los tejidos o ser un obstáculo en la intubación. Al retirarlo, un método simple para evitar que la perforación se cierre, es la colocación de un hilo de nylon o un catéter epidural muy fino a modo de anillo $(1,31,32,33)$.

\section{AGRADECIMIENTOS}

Al Dr. Dan Grauer Amir, por su inestimable ayuda.

\section{BIBLIOGRAFÍA}

1.- Peticolas T, Tilliss TSI, Cross-Poline GN. Oral and perioral piercing: A unique form of self expression. J Contemp Dent Pract, 2000; 1 (3): $1-10$.

2. Guiard-Schmid JB, Picard H, Slama L, Maslo C, Amiel C, Pialoux G, Lebrette MG, Rozembaum W. Piercing and its infectious complications. A public health issue in France. Press Med 2000 Nov 18; 29 (35): 1948-56.

3. Sean T, Carroll MD, Riffenburgh RH,Roberts TA, Myhre EB. Tattoos and body piercings as a indicators of adolescent risk-taking behaviours. Pediatrics, June 2002; 109 (6): 1021-7.

4. Chambrone L, Chambrone LA. Gingival recessions caused by lip piercing:case report. J Can Dent Assoc, 2003; 69 (8): 505-8. 
5. Boardman R, Smith RA. Dental implications of oral piercing. Ca Dent Ass J, 1997; 25 (3): 203-7.

6. Er N, Özkavaf A, Berberoglu A, Yamalik N. An unusual cause of gingival recession:oral piercing. J Periodontol 2000; 71: 1767-9.

7. Dibart S, De Feo P, Surabian G, Hart A, Capri D, Su M-F. Quintessence Int, 2002; 33: 110-2.

8. Farah CS, Harmon DM. Tongue piercing: case report and review of current practice. Aus Dent J, 1998; 43 (6): 387-9.

9. Ram D., Peretz, B.Tongue Piercing and insertion of metal studs: three cases of dental and oral consequences. J Dent Child, 2000; 67 (5): 326-9.

10. Theodossy T. A complication of tongue piercing. Br Dent J, 2003; 194 (10): 551-2.

11. Marcoux D. Apperance, cosmetics, and body art in adolescents. Dermatol Clin, 2000 Oct; 18 (4): 667-73.

12. De Moor RJ, De Witte AM, De Bruyne MA. Tongue Piercing and associated oral and dental complications. Endod Dent Traumatol, 2000; 16 (5): 232-7.

13. Botchway C, Kuc L. Tongue piercing and associated tooth fracture. J Can Dent Assoc, 1998; 64: 803-5.

14. Schultz H. Brazil's big-lipped Indians. National Geographic Magazine, 1962;121 (1):119-25.

15. Mayers LB, Judelson DA, Moriarty BW, Rundell KW. Prevalence of body art (body piercing and tattoing) in university undergraduates and incidence of medical complications. Mayo Clin Proc 2002 Jan;

16. Ferguson H. Body piercings. Br Med J 1999; 319: 1627-9.

17. American Dental Association,Current Policies, Prevention and Health Education, Policy Statement on intraoral/perioral Piercing, Chicago, American Dental Association, 1998:743.

18. BoschX. Catalonia regulates body artist'work. The Lancet, 1998; 352: 1454.
19. Establishing the sanitary regulations applicable to tattoo and /or piercing establishments (catalan). En: Decree 28/2001 of January 23, DOG (Diari Oficial de la Generalitat de Catalunya) no3318 of February 1,200177(1):29-34

20. Price SS, Lewis MW. Body piercing involving oral sites. J A D A, 1998 Jan;129 (1):16.

21. O'Dwyer JJ, Holmes A. Gingival recession due to trauma caused by a lower lip stud. Br Dent $\mathrm{J}$ 2002; 192 (11): 615-6.

22. Books JK, Hooper KA, Reynolds MA. Formation of mucogingival defects associated with intraoral and perioral piercing. JADA, July 2003; 134: 837-43.

23. Lhotka CG,Szekeres T, Fritzer-Szekeres $M$, Schwraz G, Steffan I, Maschke M, et al. Are Allergic Reactions to Skin Clips associated with delayed Wond Healing?. Am J Surg, 1998; 176 (4): 320-3.

24. Chimenos E, Batlle I, Velásquez S et al. Estética y cultura: patología bucal asociada a ciertas modas "actuales". Medicina Oral, 2003; 8: 197-206.

25. Rogero SO.,Higa OZ, Saiki M, Correa OV, Costa I. Citotoxicity due to corrosion of ear piercing studs. Toxicology in vitro 2000, Dec; 14 (6): 497 504.

26. Kretchmer MC, Moriaty JD. Metal piercing trought the tongue and localitzed loss of attachment. A case report. J Periodontol, 2001; 72 (6): 831-33

27. Sardella A, Pedrinazzi M, Bez C, LodiG. Labial piercing resulting in gingival recession. A case series. J Clin Periodontol, 2002; 29: 961-3.

28. Campbell A, Moore A, Williams E, Stephens J, Tatakis DN. Tongue piecing: Impact of time and barbell stem length on lingual gingival recession and tooth chipping. J Periodontol, 2002; 73: 289297.

29. Keogh IJ, O'Leary G. Serious complication of tongue piercing. J Laryngol Otol, 2001; 115: 233-4

30. Gay Escoda C, Berini Aytes L. Normas Generales de tratamiento de la infección odontógenica. En: 
Tratado de Cirugía Bucal. Ediciones Ergón 1999; p.636.

31. Brown DC. Anesthesic considerations and a safe solution. Anesthesiology, 2000; 93 (1): 307-8.

32. Oyos TL. Intubation sequence for patient presenting with tongue ring. Anesthesiol, Jan, 1998; 88 (1): 279.

33. Rosenberg AD, Young MRN, Beirnstein RL. Tongue Rings: Just Say No. Anesthesiol, Nov 2001; 89: 1279.

\section{CORRESPONDENCIA}

Dra. Helena Viñals Iglesias.

Paseo de San Juan $80,2^{\circ} 1^{\text {a }}$. 08009.Barcelona

Telf. 93.246.33.76 / Telf-Fax: 93.346.39.79

e-mail: hvinyals@ infomed.es 